\title{
Estudando os falsos amigos e fazendo novos amigos: uma aproximação aos dicionários bilíngues espanhol/português
}

\author{
Mariana Francis \\ Universidade Estadual do Oeste do Paraná \\ marianafrancis@gmail.com \\ Josiane Soares Rodrigues \\ Universidade Estadual do Oeste do Paraná \\ JOSI_ANYNHA@YAHOO.COM.BR
}

\section{Resumo}

Nesse texto se relatam experiências de trabalhos realizados no marco do "Programa de Formação e Ensino de Línguas PROFEL” evinculados ao projeto “Observatório da Educação - Núcleo de Pesquisa eExtensão: Formação Continuada em Leitura, Escrita e Oralidade" (CAPES/INEP). O objetivo principal da proposta foi elaborar e aplicar atividades didáticas que envolvessem o uso de dicionários bilíngues (DB) para o estudo dos falsos amigos linguísticos na disciplina de Língua Espanhola, em ambiente escolar. Mediante o estudo de pressupostos teóricos quanto à Lexicografia Pedagógica, foram selecionados, elaborados, aplicadose divulgados, entre alunos e professores de escolas públicas, materiais didáticos destinados a incentivar o desenvolvimento de habilidades de consulta em DB. Essa proposta foi desenvolvida no período de agosto de 2011 a julho de 2012, obtendo-se como resultados a aproximação dos participantes ao $\mathrm{DB}$, enquanto gênero textual, promovendo um aproveitamento das informações que ele disponibiliza e, em consequência, propiciando uma melhoria no ensino e na aprendizagem da língua espanhola.

Palavras-chave: Lexicografia pedagógica. Dicionários bilíngues. Língua espanhola. Falsos amigos.

\section{Studying false friends and making new friends: an approach to spanish / portuguese bilingual dictionaries}

\begin{abstract}
This text will report experiences accomplished in the development of the "Program of Teacher Formation and Language Teaching - PROFEL" and linked to the project "Observatory of Education - research center/extension: continuing education in reading, writing and orality" (CAPES/INEP). The main objective of the proposal was to develop and implement educational activities involving the use of bilingual dictionaries (BD) to study linguistic false friends in the Spanish Language in the school environment. Instructional materials were selected, designed, implemented and disseminated among students and public school teachers in order to encourage the development of skills in BD search. This was done by the study of theoretical assumptions regarding the Pedagogical Lexicography. This proposal was developed between August 2011 and July 2012, resulting in the approach to BD by the participants, concerning textual genre, promoting the use of the information available and, therefore, providing an improvement in the process of teaching and learning the Spanish language.
\end{abstract}

Keywords:Pedagogical lexicography. Bilingual dictionaries. Spanish language. False friends. 


\section{Extensio $\mid$ Dossier}

\section{INTRODUÇÃO}

Este artigo é resultado das reflexões propiciadas pela aplicação da atividade de extensão intitulada "O Uso de Dicionários Bilíngues na Aula de Espanhol como Língua Estrangeira”. Essa atividade foi proposta na forma de projeto para obtenção de bolsa outorgada pelo "Programa Institucional de Bolsas UNIOESTE/ PROEX", no marco do "Programa de Formação e Ensino de Línguas - PROFEL".

O PROFEL consiste em um programa de extensão cujo objetivo é promover a articulação entre a Universidade Estadual do Oeste do Paraná (UNIOESTE), campus de Foz do Iguaçu, e a comunidade multinacional dessa cidade, mediante o cumprimento de atividades vinculadas ao ensino e à aprendizagem de línguas. A proposta se justifica pelas características peculiares que conformam a cidade, por constituir fronteira com a Argentina e o Paraguai, além de congregar grandes grupos de imigrantes de diversos países e de ser um dos locais turísticos mais visitados do Brasil. Todos esses aspectos promulgam a região como centro de convergência da multiplicidade linguística, percebendo-se a necessidade diária de muitos habitantes de se comunicarem numa segunda língua.

A realização de algumas atividades envolveu, ainda, o projeto "Observatório da Educação - Núcleo de Pesquisa e Extensão: Formação Continuada em Leitura, Escrita e Oralidade" (CAPES / INEP), do qual essa equipe participa na condição de voluntariado.

O "Observatório da Educação" é um projeto de cunho multidisciplinar que objetiva alavancar a melhoria do ensino público, mediante ações que atendam o desenvolvimento de habilidades comunicativas dos alunos, tendo como foco de aplicação o Colégio Estadual Ipê Roxo, instituição localizada em bairro próximo às instalações da universidade supracitada.

A conjuntura dessas atividades possibilitou a concretização do projeto sobre os usos dos dicionários bilíngues (DB), cujos objetivos foram: a) elaborar materiais didáticos tendo em vista pressupostos da Lexicografia Bilíngue e da Lexicografia Pedagógica (LP); b) aplicar atividades que envolvam esses materiais, promovendo o ensino e a aprendizagem de habilidades de consulta e aproximando o DB de alunos e professores de espanhol; c) analisar o resultado da aplicação desses materiais para reflexões quanto às contribuições do DB para o processo do ensino e da aprendizagem do espanhol como Língua Estrangeira (LE); d) registrar os materiais em bancos de dados disponíveis para a consulta dos interessados, possibilitando a sua aplicação em estágios curriculares, no ensino regular (médio e superior), em cursos de atualização de professores, entre outros.

Mas, qual é a importância de se ensinar os usos do DB? Para responder a essa interrogativa, é necessário resgatar algumas informações e conceitos que envolvem a história desse instrumento de consulta como obra de cunho pedagógico.

Nos últimos 60 anos, os DB têm adquirido um papel cada vez mais relevante para a recepção e produção linguística em LE, como mediadores da aprendizagem de idiomas. Segundo Hwang (2010), o DB constituiu um instrumento da maior importância no âmbito pedagógico desde seus ancestrais mais distantes, utilizados pelos povos mesopotâmicos há 4.500 anos, os quais nada mais eram que listas bilíngues de vocabulário gravadas em tabuinhas de argila.

Na década de 1950, com o advento da tecnologia e a popularização do turismo, iniciou-se uma crescente demanda pelo ensino de línguas e, consequentemente, por DB mais portáteis, econômicos e adequados a essa necessidade (DURAN; XATARA, 2008).

Inaugura-se, nesse período, uma nova disciplina, a Lexicografia Pedagógica, que possui como objeto de estudo os dicionários direcionados para o ensino de línguas. Nessa perspectiva, embora se reconheça sua relevância como material didático, o DB é um instrumento a ser aperfeiçoado, pois, ao analisar o seu funcionamento em sala de aula, percebem-se inadequações e deficiências próprias de uma ferramenta que trabalha com elementos complexos, diversificados e mutáveis: as línguas.

Para a análise dessas inadequações, a Metalexicografia, fase teórica da atividade lexicográfica (WELKER, 2004), apresenta duas vertentes que, em especial, são de interesse para o projeto: uma seção dedicada à 
crítica dos dicionários e outra voltada ao estudo do uso de dicionários. No que se refere às pesquisas sobre os usos dos dicionários, Welker (2006) aponta para cinco variáveis a serem consideradas: o tipo de usuário, o tipo de dicionário, as línguas envolvidas, a existência de habilidades de uso e o tipo de situação de uso.

Pelos argumentos elencados, percebe-se que os DB são obras que estão fortemente vinculadas ao ensino, que sofreram adaptações se tornando acessíveis aos estudantes e que, apesar da sua relevância como material para o ensino de línguas, possuem limitações, sendo necessário, para sua melhoria, o estudo metodológico de seus usos.

Em virtude da cidade de Foz do Iguaçu compartilhar dupla fronteira com nações hispanófonas, a aprendizagem da língua espanhola e seu aperfeiçoamento são sumamente importantes para os habitantes da região. Nesse sentido, a aplicação das atividades planejadas visou atender esse público no que se refere a uma escolha adequada e a um uso eficaz do DB como ferramenta para o desenvolvimento de habilidades linguísticas que propiciam uma comunicação eficiente.

Até o momento, justificou-se apenas a necessidade de uma aproximação aos DB, mas qual é a importância de se estudar os falsos amigos linguísticos (FA) do espanhol e do português nesse contexto?

Antes de responder, faze-se necessário esclarecer o termo "falso amigo", o qual, no ensino de línguas, refere-se a palavras de dois idiomas com forma igual ou semelhante, mas que diferem, entre si, em um ou mais significados. Segundo afirma Durão (2002), em línguas tipologicamente próximas, como é o caso do espanhol e do português, o aprendiz costuma se apoiar com maior frequência na sua língua materna (LM) para se expressar na LE. Por esse motivo, o FA constitui uma verdadeira armadilha para a comunicação interlinguística, pois aparenta ser transparente ao entendimento, quando, na verdade, é um ponto opaco que induz a equívocos, dificultando a eficácia comunicativa. Por esse motivo, diversas atividades planejadas no projeto preveem o uso do DB no estudo dos FA, buscando evidenciar a dificuldade representada por esses elementos linguísticos e os benefícios e limitações que possuem os DB para esclarecê-los nos diferentes contextos de uso.

Sendo o objetivo deste artigo apresentar e comentar as experiências da elaboração e aplicação de jogos didáticos nos quais se trabalhem, especificamente, os FA, foram escolhidas duas atividades que constituem tarefas de interpretação textual, descritas na sequência.

\section{MATERIAL E MÉTODOS}

Os jogos que aqui se apresentam têm por objetivos: identificar os FA do espanhol com relação ao português, expostos nos textos; praticar a decodificação (recepção) linguística solicitando sua tradução ao português com o auxílio dos DB; aplicar os conhecimentos adquiridos mediante a identificação desses FA de forma descontextualizada.

Para a confecção dos jogos, foi necessário, inicialmente, escolher dois textos em espanhol que possuíssem um grande número de FA. Optou-se por dois deles, extraídos de livros didáticos, mas que circulam também na internet, por serem considerados amenos e divertidos. O primeiro texto tem como título "Eu não falo português" e foi escrito, originariamente, por Daniel Samper, jornalista e escritor colombiano, sendo a versão utilizada para realizar a atividade a que oferecem Bruno e Mendoza (2002). O segundo texto, "La presunta abuelita", é de autoria de Bataburu e Oliveyra (2004) e foi retirado da obra original.

Após a escolha dos textos, foram confeccionadas cartelas com cartões coloridos, nas quais se transcreveram os falsos amigos presentes nos textos. Os materiais utilizados deveriam ser simples e acessíveis, para facilitar a sua reduplicação, pois o objetivo era que os professores de língua espanhola pudessem construir esses jogos com rapidez. Apesar de sua aparente simplicidade, alguns cuidados se fizeram necessários na elaboração das fichas e na escolha dos dicionários a serem utilizados, a fim de garantir o sucesso das atividades. Alguns deles foram: escolher apenas uma cor de cartão para cada idioma e indicar qual corresponde à LE; verificar a existência, nos DB, dos FA selecionados para o jogo, evitando buscas infrutíferas; produzir 


\section{Extensio $\mid$ Dossier}

cartelas suficientes para desenvolver as atividades em pequenos grupos.

O material didático elaborado sobre o texto "Eu não falo português" (SAMPER apud BRUNO; MENDOZA, 2002) está composto por 16 pares de FA. Foi utilizado cartão azul para as palavras em espanhol e amarelo para as palavras em português, conforme se apresenta na Ilustração 1, na qual se selecionaram alguns pares como exemplos.

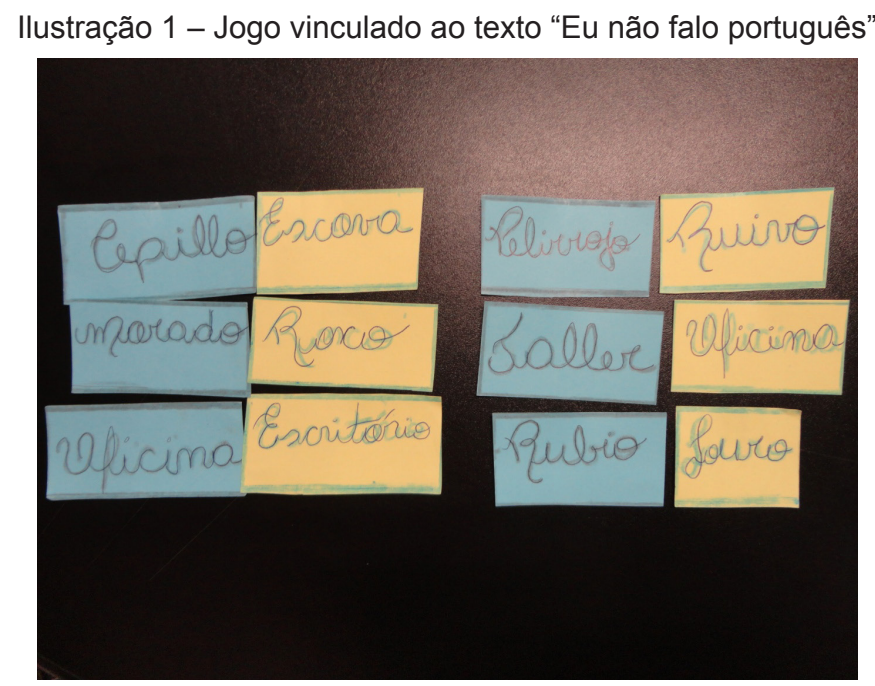

Fonte: elaborado pelas autoras.

O objetivo do jogo é relacionar os pares de FA de acordo com sua equivalência dentro do contexto estudado, utilizando os DB, em caso de haver dúvidas. Embora haja uma leitura prévia do texto, no qual, as palavras conflitavas aparecem em ambas as línguas, no momento do jogo, para solucionar a atividade, os participantes tiveram à disposição apenas os DB.

O segundo material, elaborado em torno ao texto "La presunta abuelita" (BATABURU; OLIVEYRA, 2004), é um jogo didático com 50 pares de falsos amigos. As palavras em português foram escritas em cartão de cor rosa e as do espanhol, em cartão de cor laranja, segundo se apresentam, como exemplo, na Ilustração 2 .

Ilustração 2 - Jogo vinculado ao texto "La presunta abuelita"

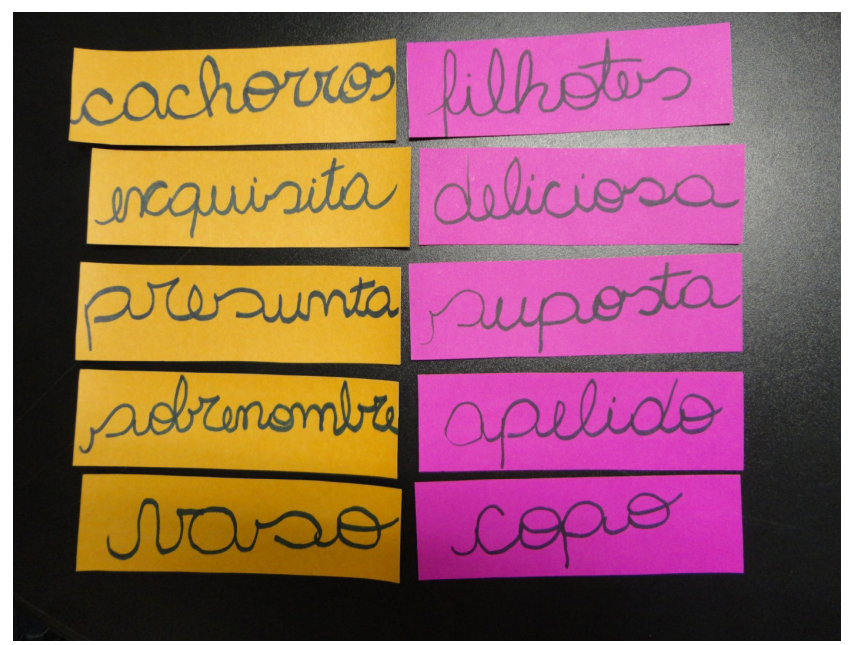

Fonte: elaborado pelas autoras. 
Nesse texto, aparecem os FA apenas do espanhol, motivo pelo qual o cuidado em oferecer equivalentes que estejam, de fato, nos DB utilizados deve ser redobrado, se o objetivo é obter êxito nas consultas.

Devido a seu caráter lúdico, essas atividades visaram, além da aprendizagem dos FA e o desenvolvimento de habilidades de consulta aos DB, conceder um momento de dinamismo e descontração à aula de língua espanhola, tornando a aprendizagem mais prazerosa e motivando o espírito cooperativo e autodesafiador.

A proposta sobre os usos dos DB nas aulas de espanhol como LE possui apenas dois integrantes: uma colaboradora bolsista e a docente orientadora, que é, também, coordenadora do programa de extensão.

A primeira atividade aqui descrita foi aplicada no marco do projeto "Observatório da Educação", durante o estágio curricular de docência da colaboradora discente para o Curso de Letras da UNIOESTE, no ano de 2011, em turmas regulares do ensino médio do Colégio Estadual Ipê Roxo.

A segunda atividade foi desenvolvida pela coordenadora do programa PROFEL, com auxílio da colaboradora discente, durante uma oficina ministrada aos professores de língua espanhola da rede pública de ensino, constituindo parte de um curso para a atualização de conhecimentos desses professores. $\mathrm{O}$ curso teve a parceria do Núcleo Regional de Educação (NRE) de Foz de Iguaçu e foi realizado no ano de 2011, nas dependências da UNIOESTE.

Em ambos os casos, os participantes foram instruídos, previamente, quanto aos usos dos DB. Explicou-se o caráter didático das obras, apontando para vantagens e limitações, assim como, também, para os componentes estruturais e funcionais desses instrumentos de consulta. Aos professores foi enfatizada a importância de apresentar detalhadamente os elementos que compõem os DB, instigar sua consulta e propiciar momentos e atividades voltados para ela. O desenvolvimento dessas habilidades propicia uma autonomia na busca por soluções aos problemas léxicos, com os quais o aprendiz se depara quando contrasta as línguas. Como consequência, obtém-se uma aprendizagem mais significativa e autodirecionada.

Em relação à aplicabilidade das tarefas nos projetos, seguem, nos próximos itens, o relato das atividades e o processo de sua efetivação e contribuição aos alunos e professores no ensino da língua espanhola.

\section{RESULTADOS E ANÁLISE}

No marco do projeto “Observatório da Educação”, foram desenvolvidas atividades durante o estágio de docência curricular em Letras, entre as quais o primeiro jogo didático mencionado, aplicadas em duas turmas do segundo ano do ensino médio, nas quais havia uma média de 35 alunos. Inicialmente, ao se trabalhar a temática dos FA em sala de aula, foram realizadas explicações destacando algumas diferenças semânticas, em uma e outra língua, alertando para os cuidados necessários para evitar equívocos na comunicação.

Percebeu-se um grande interesse dos alunos pela temática, desde as primeiras aulas, pois, ao se solicitar a tradução intuitiva para o português de frases que continham FA, muitos dos aprendizes traduziam, equivocadamente, utilizando significados de sua LM para as palavras conflitavas.

Após essa percepção, foram propostas diversas atividades explicando e incentivando o uso dos DB disponibilizados pela escola, apontando para a necessidade de se lerem os textos externos (apresentação, introdução, lista de siglas e símbolos, entre outros), a fim de se aproximar às informações neles contidas. Entende-se que "[...] o dicionário é um texto e, como tal, se organiza por meio de diferentes estruturas" (BEVILACQUA, 2006, p. 109). É preciso que esse texto seja apresentado ao aluno, para poder ser compreendido, explorado e manuseado com domínio, em favor da evolução lexical da língua objeto (LO) desse aprendiz.

Durante as explicações, deu-se ênfase ao fato de os DB apresentarem equivalentes, ao invés de significados, e ao uso da seção que vai do espanhol para o português em situações que demandam a compreensão (decodificação) textual.

Antes de aplicar o primeiro jogo, foi realizada, ainda, uma prática de busca de alguns FA que seriam solicitados. O objetivo era chamar a atenção para a falibilidade dessas obras, pois, nos DB escolares dis- 


\section{Extensio $\mid$ Dossier}

poníveis na escola, falta uma palavra que seria requerida, na seção que se direciona do espanhol ao português, mas se encontra na seção oposta, do português ao espanhol. Uma aluna percebeu esse fato e comentou que não havia, no DB, o lema "berro" na parte destinada à decodificação, mas que estava como equivalente de "agrião" na seção dedicada à codificação. Nesse momento, já previsto, a acadêmica trabalhou a criticidade quanto ao dicionário, apontando para suas limitações, justamente quanto a um assunto extremamente relevante para a compreensão textual, visto que a essa obra em especial faltava sistematicidade na apresentação das informações.

Como atividade final para avaliar a apreensão de conteúdos sobre os FA, foram indicadas a leitura e a compreensão do primeiro texto, aplicando-se a atividade previamente planejada. Foram notórias a agilidade e eficácia com as quais os alunos solucionaram o jogo, considerando-se a complexidade da temática e o fato de eles estarem cientes quanto aos perigos da aparente transparência lexical das línguas envolvidas. Os alunos evidenciaram um grande interesse e satisfação ao concluírem a tarefa, sendo muito proveitosa não só na apreensão do conhecimento linguístico, mas, também, na instalação da participação grupal das turmas e do cultivo de um crescente espírito de equipe. Os alunos demonstraram confiança, tanto nos seus conhecimentos quanto no uso dos $\mathrm{DB}$, dirigindo-se espontaneamente ao material de consulta e respondendo com propriedade ao se realizar a correção oral da tarefa.

O segundo jogo foi aplicado no marco das "IV Oficinas Temáticas Pedagógicas para Professores de Língua Espanhola da Rede Pública”, curso de extensão ministrado para 25 professores da área. Um dos objetivos dessa atividade foi orientar esses profissionais e propor-lhes materiais que os auxiliem em sua prática docente, mostrando como instruir seus alunos para que ampliem suas habilidades no uso dos DB, dentro e fora das aulas de espanhol.

Antes de apresentar o texto, os professores receberam informações e orientações quanto aos componentes e funcionalidades dos $\mathrm{DB}$, assim como, também, quanto às suas vantagens e limitações. Devido ao conhecimento que os professores já possuem sobre a LO, foi solicitado, no desenvolvimento da tarefa, que se ativessem, apenas, às informações obtidas nos dicionários, omitindo intuições ou conhecimentos prévios.

O texto proposto foi desmembrado em cinco partes, e os participantes se dividiram em grupos, os quais se ocuparam cada um de uma parte. Os professores resolveram a tarefa, mas em ocasiões referiram que só seria possível realizá-la pela intuição ou com conhecimentos prévios sobre a língua.

Havia diversos dicionários disponíveis, e, o curioso, foi observar que os professores ficavam inconformados ao perceberem que alguns deles não possuíam as palavras procuradas, situação já prevista pela ministrante, principalmente, nas obras de editoras mais afamadas. Em certos casos, o problema era identificar o equivalente adequado ao contexto, sendo mais elogiados os DB que apresentavam exemplos de uso em ambas as línguas, indicações de uso ou esclarecimentos.

Após ser feita a correção, realizou-se um debate sobre a adequação dos $\mathrm{DB}$ a públicos e contextos de uso determinados, sobre a escolha de DB para o ensino e a aprendizagem do espanhol como LE e sobre os benefícios de se trabalhar com essas obras de consulta na sala de aula, orientando e incentivando seu uso.

As experiências evidenciaram que os DB escolares são instrumentos úteis para estudar os FA, desde que trabalhados metodicamente, respeitando e estudando as particularidades que cada obra possui.

Nos contextos trabalhados, os alunos e os professores demonstraram interesse no uso dessas obras para realizar atividades e praticar a compreensão da leitura. Após a instrução e a prática com jogos didáticos, os quais foram cuidadosamente elaborados, os alunos demonstraram desenvolvimento nas habilidades de consulta e internalização dos conteúdos propostos, e os professores expressaram agrado em trabalhar, ao mesmo tempo, de forma didática e com conteúdos teóricos para a orientação quanto ao uso do DB como material auxiliar na aprendizagem. 


\section{Considerações Finais}

O projeto objetivou a confecção e divulgação de jogos educativos que instiguem a busca de informações nos DB, como fortes aliados do sucesso do ensino e da aprendizagem da língua espanhola como LE.

Segundo Tono (apud WELKER, 2006), no que se refere às pesquisas sobre os usos dos dicionários, a motivação e as estratégias de aprendizagem são fatores a serem considerados, além das habilidades linguísticas. Essa afirmação reflete diretamente na postura e planejamento do professor, pois, se o profissional pensar no DB somente como um complemento aos estudos gramaticais, sem planejar atividades que propiciem a necessidade de consultar o dicionário, estará promovendo o desinteresse dos seus alunos pela procura por essas obras.

Entende-se que, embora possuindo falhas e inadequações, os DB são de estrema utilidade para a aprendizagem de línguas, em especial para esclarecer certos pontos obscuros, como, por exemplo, os FA. Nesse sentido, o professor deve propiciar situações de consulta de forma sistemática, instigante e motivadora, oferecendo diversas formas de aprendizagem e incentivando o autodidatismo.

A experiência mostrou que, ao estudar os "falsos amigos" linguísticos, é possível se aproximar de "verdadeiros amigos", os DB, os quais podem ser grandes aliados para o ensino e a aprendizagem de línguas estrangeiras.

\section{REFERÊNCIAS}

BARTABURU, María Eulalia Alvez; OlIVEYRA, Guillermo Alvez de. Español en Acción: tareas y proyectos. São Paulo: Hispania, 2004.

BEVILACQUA, Cleci Regina. Aspectos teóricos e reflexões sobre dicionários bilíngues português-espanhol e espanhol-português. In: ROTTAVA, Lucia; SANTOS, Sulany Silveira dos (Orgs.). Ensino e aprendizagem de línguas: língua estrangeira. Coleção linguagens. Ijuí: Unijuí, 2006, p. 107-114.

BRUNO, Fátima Cabral; MENDOZA, Maria Angélica. Hacia el espanhol: curso de lengua y cultura hispánica - nivel intermedio. 2. ed. São Paulo: Saraiva, 2002.

DURAN, Magali Sanches; XATARA, Claudia Maria. Reflexos da evolução do ensino de línguas na lexicografia bilíngue. Trabalhos em Linguística Aplicada. Campinas, n.47, v.1, p. 241-250, 2008.

DURÃO, Adja Balbino de Amorim Barbieri. Por detrás de la transparencia existe una opacidad! La lectura por estudiantes brasileños de textos redactados en español. Anuario brasileño de estudios hispánicos, Brasília, n. 12, p. 13-28, 2002.

HWANG, Álvaro David. Lexicografia: dos primórdios à nova lexicografia. In: HWANG, Álvaro David; NADIN, Odair Luiz (Org.). Linguagens em interação III: estudos do léxico. Maringá, PR: Clichetec, 2010. p. 33-45

WELKER, Herbert Andreas. Dicionários: uma pequena introdução à lexicografia. Brasília: Thesaurus, 2004.

WELKER, Herbert Andreas. Usos dos dicionários: panorama geral das pesquisas empíricas. Brasília: Thesaurus, 2006. 